Article

\title{
"Girl Power": Gendered Academic and Workplace Experiences of College Women in Engineering
}

\author{
Kathleen N. Smith * (D) and Joy Gaston Gayles \\ Department of Educational Leadership, Policy, and Human Development, College of Education, \\ North Carolina State University, Raleigh, NC 27695, USA; jggayles@ncsu.edu \\ * Correspondence: knsmith8@ncsu.edu; Tel.: +1-919-513-0924
}

Received: 27 November 2017; Accepted: 7 January 2018; Published: 10 January 2018

\begin{abstract}
Women in engineering continue to experience bias in the field. This constructivist case study uses feminist theory to examine the gendered experiences of graduating senior women engineering students in academic and workplace environments. In each setting we identified three subthemes; in academia: "I don't think my education is any different," "Being underestimated constantly," and "You don't want to be seen as getting advantages"; in the workplace: "Oh, you're a girl," "There's a lot of sexism," and Benefits of "girl power." Overall, findings indicate that women experience bias in both settings, often via implicit bias in academia and with instances of implicit bias, sexism, and sexual harassment occurring even more often in the workplace through internship experiences. The article concludes with suggestions for practice, future research, and strategies to create supportive academic and workplace experiences and environments for women engineers.
\end{abstract}

Keywords: women; engineering; STEM; undergraduate; academia; work; internships; bias; sexism

\section{Introduction}

Despite the growing numbers of women earning degrees in engineering, women remain vastly underrepresented in engineering fields. Women comprise only $20 \%$ of students graduating with bachelor's degrees in engineering (National Science Foundation 2017) and just $12 \%$ of the engineering workforce (Corbett and Hill 2015). This underrepresentation is two-fold; not only are women entering these fields at far lower rates than men (Sassler et al. 2017) but they are leaving them at higher rates as well (Buse et al. 2013; Frehill et al. 2008; Garibay et al. 2013; Xu 2017).

Why is it that women who are talented in math and science shy away from or leave engineering majors and careers? An American Association of University Women report on women's success in engineering and computing suggests that women who persist in science and engineering are not all that different from women who decide to leave (Corbett and Hill 2015). The major difference between staying and leaving has been found to have less to do with the women themselves and more to do with the academic and workplace environments where they attend school and pursue careers (Buse et al. 2013; Fouad et al. 2016; Hewlett 2008; National Research Council and National Academy of Engineering [NRC/NAE] 2014; Rhoton 2011). Throughout the literature on women's persistence in science, technology, engineering, and math (STEM) fields, a host of structural and cultural barriers contribute to the high prevalence of gender bias in these fields, with direct implications for women's self-efficacy, experiences, opportunities, and success, particularly in engineering (Buse et al. 2013; Haines et al. 2001; Hall and Sandler 1982, 1984; Morris and Daniel 2008; Sax et al. 2015; Xu 2013, 2015, 2017).

The importance of increasing the number of women in engineering is supported by workforce demands, which are outpacing the number of individuals earning degrees, especially in computing and engineering (Corbett and Hill 2015). In order to meet this high demand, increasing diversity 
within the field must be a priority. More importantly, increasing diversity in engineering fields is critical to accomplishing greater social equity, as well as achieving enhanced innovation, creativity, and productivity in problem solving (Hong and Page 2004; Office of Science and Technology Policy 2016; Sargent 2014).

While the significant underrepresentation of women in STEM has received considerable attention in recent years, gaps in the understanding of women's experiences in these fields persist. Much of the present literature regarding women in science and engineering focuses broadly across the wide range of STEM fields, thus failing to capture dynamics unique to more specific areas and fields such as engineering. Because women are particularly underrepresented in engineering and computing in comparison to other STEM industries (Corbett and Hill 2015; National Science Foundation 2017), understanding this disparity and the unique experiences of women in these areas is particularly critical to reducing chilly climates and creating more culturally inclusive environments to increase women's persistence, representation, and success in male-dominated fields.

The present study is derived from a larger project that explored the experiences of graduating senior women in engineering who accepted full-time employment post-graduation (Smith and Gayles 2017). In the initial case study, gender dynamics arose as a primary theme related to women's career decisions but rich nuances regarding gender dynamics in these environments remained, warranting additional analysis. In the present paper, we focus specifically on the gendered academic and workplace experiences of the women in the study using a feminist theory lens. While existing research informs our knowledge of women in engineering academic settings (e.g., Chen and Weko 2009; Eagan et al. 2013; Hall and Sandler 1982, 1984; Hughes 2010; Litzler and Young 2012; Marra et al. 2009; Morris and Daniel 2008; Sheppard et al. 2010), and women in engineering workplace settings (e.g., Buse et al. 2013; Fouad et al. 2016; Hewlett et al. 2008; Kahn and Ginther 2015; Wang and Degol 2013), very little research considers the intersection of these two environments on women engineering students' experiences and decisions to continue in the field after college graduation, a critical juncture in field persistence (Amelink and Creamer 2010; Garibay et al. 2013; Lichtenstein et al. 2009; Winters et al. 2012). Further, very few studies focus specifically on women's career-related experiences in internships and co-ops, despite the high prevalence of these field experiences within engineering majors.

Results from our analysis highlight three themes related to women's experiences as engineering undergraduates in academic settings, and three in workplace settings through internships and co-ops. In academic settings, several participants perceived overall equitable educational experiences with some stating that women may have an "advantage" based on the availability of student organizations and other resources aimed towards supporting women in STEM fields. However, all participants shared examples of bias where their engineering knowledge was underestimated or demeaned, most frequently by male peers. Further, despite the availability of campus resources designed specifically for women in STEM majors, participants generally did not engage with these organizations in an attempt to prove their personal merit and to avoid the perception of advantage due to gender. In the workplace, themes revealed that gender-related dynamics may be especially prevalent. In these settings participants reported experiencing first impressions that were informed by colleagues' gendered stereotypes and negative assumptions about their abilities, initial reactions that tended to adversely affect relationships with colleague and participants' comfort in these settings. Women reported experiencing more incidences of sexist and sexually harassing behaviors in male-dominated workplaces as compared to their academic settings, also feeling greater comfort and support in the rare occasions where they worked with other women engineers. This paper concludes with recommendations for creating more positive and supportive environments to promote greater retention and success for women in engineering.

\section{Literature Review}

The significant underrepresentation of women in engineering can be attributed to structural and cultural barriers within the academic and professional settings that women encounter in engineering, 
barriers that negatively affect their persistence in these fields (Buse et al. 2013; Fouad et al. 2016; Hewlett 2008; Rhoton 2011). Unfortunately, there is a long history of discrimination of women and minorities within high-paying professions, including engineering, which are most often dominated by men (Blair-Loy 2013). Further, evidence supports that women who work in male-dominated fields experience gendered barriers that not only impede their success, but also make it difficult to combat inequality within the workplace (Amon 2017; Powell et al. 2009; Rhoton 2011).

The pollution theory of discrimination (Goldin 2014) is a plausible perspective that untangles how discrimination manifests in these settings. The theory suggests that people within an occupation might perceive that the prestige of the field is diminished, threatened, or "polluted" when underrepresented groups enter, as they are perceived to have inferior qualities to the dominant group. Pollution attribution suggests that rather than accepting that individuals from underrepresented backgrounds meet the standards for being hired, the field's standards are instead lowered with the entry of individuals from underrepresented groups, thereby polluting the quality of the profession. In these circumstances, underrepresented groups are judged based on biased perceptions and stereotypes instead of qualifications and skills. The perception of lower standards in the field can lead to discrimination in ways that keep underrepresented groups out of high-paying occupations (Milkman et al. 2015). There is evidence of the pollution theory of discrimination in the form of bias, or unequal treatment of underrepresented groups based on preconceived judgments and/or stereotypes (Greenwald and Krieger 2006), such as women in engineering fields. In this literature review, we discuss three types of bias commonly found in research on women in science and engineering: (1) Implicit bias; (2) sexism; and (3) sexual harassment.

Implicit bias refers to subconscious attitudes that inform how we they think and behave towards others (Greenwald and Banaji 1995; Greenwald and Krieger 2006). From an early age, people are exposed to stereotypes and preconceived judgments about various groups of people and, over time, these perspectives lead to ill-informed judgments. A major problem is that the information we learn about different groups of people is often inaccurate and/or incomplete (Tatum 1997). Moreover, our judgments and perceptions about people unlike ourselves shape how we behave towards people who are different from us (Greenwald and Banaji 1995; Heilman 2012).

Sexism, another form of bias, can be defined as the systematic and unearned advantages given to men that are rooted in privilege and power (Glick and Fiske 2001). Sexism can be hostile or benevolent, and both forms have negative effects on the academic and workplace experiences of women in science and engineering (Reilly et al. 2016). Benevolent sexism is characterized by the subtle ways in which women who embrace conventional gender roles are treated favorably, shown affection, and protected by men, perpetuating the ideology that women need help from men. There are also hostile forms of sexism characterized by discriminatory behavior rooted in a strong dislike or aversion toward women who hold positions of power (Glick and Fiske 2001).

Sexual harassment refers to direct or indirect sexual conduct that is not welcomed. Unwanted sexual advances, physical contact, sex-based taunting, denigration, and inappropriate comments create a hostile environment. Unfortunately, sexual harassment is widespread in science and engineering fields, with over half of women in these fields reporting incidences (Hewlett et al. 2014). Even with the high instance rate of sexual harassment reports, research shows that some women do not report sexual harassment when it happens (Hunter 2006). Instead, women tend to use coping mechanisms such as ignoring sexual harassment or, worse, seeing it as a part of the job and not reporting it in order to maintain good working relationships with their colleagues (Chamberlain et al. 2008; McLaughlin et al. 2012; Stainback et al. 2011).

While each form of bias is associated with different types of perceptions and detrimental behaviors, all have directly negative implications for women's success and persistence in engineering fields. Research discussed below provides insight into how these concepts relate to women in engineering workplace and academic settings. 


\subsection{Academic Persistence for Women in STEM}

Women in engineering majors enter college with the same levels of interest and intent to persist in the major as male peers, yet fewer women complete undergraduate degrees in STEM fields and persist into related careers (National Science Board 2016). The structural and cultural barriers to persistence and overall success are receiving greater attention from scholars today, with more researchers seeking to understand the institutional systems that constrain women in science and engineering, yet enable men (Anicha et al. 2017; Powell et al. 2009; Rhoton 2011). Overall, research shows that women who have positive experiences in STEM majors via supportive faculty members and peers, research experiences, or participation in engineering organizations are more likely to continue taking STEM classes, complete degrees and continue on to post baccalaureate STEM careers in comparison to those who do not (Beyer 2014; Gayles and Ampaw 2016; Hughes 2010; Kezar and Holcombe 2017; Litzler and Young 2012; Marra et al. 2009; Neumann et al. 2016; Ro 2011).

Many women in science and engineering report experiences with discrimination and bias that make it difficult to persist and succeed in their majors. Women in science and engineering have a long history of feeling marginalized, isolated, and subject to stereotype threats within their majors, a feeling that tends to grow over time (Marra et al. 2009; Neumann et al. 2016). Favoritism and differential treatment also detract from positive experiences that increase persistence and academic success for women, as male and female faculty in science and engineering have been found to favor and be more responsive to male students in comparison to females (Milkman et al. 2015; Moss-Racusin et al. 2012). Further, reports of bias in the form of sexual harassment from classmates and faculty are all too common for undergraduate women in science and engineering (Morris and Daniel 2008).

Differential treatment and bias towards women in science and engineering also have negative underlying consequences for women's perceptions of their own abilities. An early study on chilly climate found that women in male-dominated fields perceived their ideas as less valuable and unwelcomed in comparison to those of male peers (Hall and Sandler 1982), and more recent work suggests that women underestimate their performance on engineering tasks compared to men (Woodcock and Bairaktarova 2015). Additional research has shown that unwelcoming environments contribute to decreased self-confidence, self-efficacy, the tendency behave in self-limiting ways that negatively impact overall success and persistence for women in science and computing (Haines et al. 2001; Morris and Daniel 2008), with gender discrimination related to lower academic performance (Beyer 2008).

\subsection{Career Persistence for Women in STEM}

Despite the growing availability of math and science programs for young girls today (e.g., Hughes 2015; Hyllegard et al. 2017), the current lack of women who choose to enter and persist into STEM careers is concerning. Several factors are associated with gender differences in career choice, many of which are linked to expectations for success and the value attached to career options, as well as sociocultural and contextual factors (Beyer 2016; Wang and Degol 2013). Wang and Degol (2013) identified characteristics such as intellectual aptitude, academic performance, future aspirations, courses taken, and engagement in STEM activities as predictors of career choice for women in STEM, as well as work-family balance and occupational preference. Related to occupational preference, women are less likely to report identifying with the tech profession (Wang and Degol 2013; Wynn and Correll 2017) and are more likely to report a higher interest in working in jobs that benefit people and society than men who report greater interest in working with objects, which tends to be more in line with STEM careers (Canney and Bielefeldt 2015; Wang and Degol 2013). Overall, women are found to place higher value on careers that help people, a finding consistent with the greater representation of women in engineering fields and careers that tend to have a higher social component, such as biomedical, environmental, and civil engineering (Canney and Bielefeldt 2015).

Related to future aspirations and occupational preferences, even among students who major in STEM fields, women are less likely to choose an occupation congruent with their major (Xu 2017), 
less likely to continue on to STEM-related graduate programs (Garibay et al. 2013) and tend to leave post-baccalaureate careers in engineering at twice the rate of men (Buse et al. 2013; Frehill et al. 2008). Many of the explanations as to why women exit STEM careers at higher rates than men are rooted in cultural and structural issues that are systemic in nature. Differences between women who persist in male-dominated fields with chilly climates and those who leave can be attributed to factors such as demanding work environments, having a high sense of self-efficacy, engineering/technical identity, occupational commitment, the ability to adapt to change, and a strong disposition of being motivated by challenges (Buse et al. 2013; Fouad et al. 2016; Ibarra 1999; Neumann et al. 2016; Wynn and Correll 2017). Women who leave engineering report experiencing heavy workloads, unclear expectations, a lack of work-life balance, and chilly climates (National Research Council and National Academy of Engineering [NRC/NAE] 2014). This lack of satisfaction has important implications; among those who left STEM jobs, women are more likely than men to report changes in professional interests as a primary reason for leaving the field (Hewlett 2008).

Both women who persist and who leave engineering report overall difficult work environments, including instances of harassment and discrimination. Research shows that women in engineering commonly experience differential treatment and marginalization, including sexist behaviors from male colleagues and supervisors, as well as social disconnection such as exclusion from networking opportunities (Amon 2017; Powell and Sang 2015; Rhoton 2011; Wynn and Correll 2017). In a study of STEM interns, women were seen as less competent, with any challenges that they encountered viewed as a confirmation of stereotypes about their ill-suitedness for STEM fields (Reilly et al. 2016). In general, women report feeling that their engineering identities are often de-emphasized in the workplace compared to their gender identities, and that they are judged more harshly based on principles consistent with the pollution theory of discrimination (Goldin 2014; Hatmaker 2013; Powell et al. 2011; Powell and Sang 2015).

There is also evidence that women in STEM careers engage in behaviors such as distancing and distinguishing themselves from other women within their work environments based on cultural norms that are informed by masculine values and traits (Rhoton 2011). An interesting paradox is that women who persist in male-dominated career fields often do so at the expense of dismantling gender inequality (Powell et al. 2009; Rhoton 2011). Rhoton (2011) found that women faculty in STEM disciplines often distance themselves from other women colleagues who engage in feminine practices as well as those who perceive the existence of gender barriers based on perceptions that feminine behaviors are not valued in the workplace and to demonstrate solidarity with the masculine occupational culture. As a consequence, women who engage in more masculine behaviors as a coping mechanism end up perpetuating problematic gendered cultures and structures instead of dismantling them (Powell et al. 2009; Rhoton 2011).

Another reality is that some women leave engineering careers due to environmental factors such as the lack of female representation, gendered norms and expectations, lack of mentoring, and difficulty balancing family and work (Cha 2013; Corbett and Hill 2015; Hewlett et al. 2008; Hunt 2016; Wang and Degol 2013). Among scientists and engineers who are not in the workforce, women are far more likely than men to attribute this to family responsibilities (National Science Foundation 2017). In a study of women engineers from 1993 to 2010, it was found that women's decisions to leave the workforce coincided with having children (Kahn and Ginther 2015). Notably, demographic factors such as being married and having children are both significantly negatively related to pay levels for women, while there is no adverse effect of these variables for men ( $X u$ 2015). Further, women in STEM are found to be at a significant pay disadvantage to men, a gap that has grown over time (Xu 2015), and one that is generally underestimated by college students (Beyer 2016).

\section{Conceptual Framework}

Feminism recognizes that injustices and discrimination based on gender have developed over time and still exist in society. To better understand and give voice to the academic and workplace 
experiences of women in engineering, we use feminist theory as a guiding framework. Feminist theory places gender at the center of the analysis (Ropers-Huilman and Winters 2011) and acknowledges that women and men have different experiences and that the oppression of women is a structural issue rooted in how society is organized (Flax 1996). Further, feminist theory gives researchers a set of tools to examine injustices that occur in society and build strong arguments in support of change (McCann and Kim 2017).

In particular, we rely on feminist standpoint theory to understand how and why gender is a structural issue related to the academic and workplace experiences of undergraduate women in engineering. Feminist standpoint theory uses the experiences of women to create knowledge and present critical reflections about how power dynamics shape social locations (Intemann 2010). Two important aspects of feminist standpoint theory are: (1) Social locations place limits on knowledge (e.g., some individuals may not have access to knowledge due to their position in society); and (2) standpoints for marginalized groups are disadvantaged (e.g., not well understood or heard by majority groups). While feminist standpoint theory has received critique in generalizing the experiences of all women whilst deeming the perspectives of marginalized groups as inherently advantaged (Hekman 1997; Intemann 2010), other standpoint theorists denounce these essentialisms, acknowledging that all people have different experiences and individual knowledge (Wylie 2003).

Feminist standpoint theory is considered a social epistemology, or an understanding derived from community interactions based on patterns of experience. Standpoints, therefore, are knowledge that is "achieved" based on "critical, conscious reflection on the ways in which power structures and resulting social locations influence knowledge production" (Intemann 2010, p. 785). Heterogeneous communities that include members of marginalized groups are seen to have greater access to critical consciousness in identifying problematic assumptions based on a greater diversity of experiences, particularly those that may counter well-represented narratives and perspectives. Thus, while all women live unique lives and have differential experiences, beliefs, and identity dimensions, women's circumstances may be attributed, at least in part, to various systems of oppression, including sexism (Intemann 2010). The centralization of women's perspectives in areas where they are underrepresented is essential to amplifying the voice of this group while employing a critical lens to examine problematic assumptions and behaviors that adversely affect their opportunity.

\section{Methods}

The present study is derived from a constructivist case study about influential experiences on the career decisions of graduating women in engineering. Within the original study, gender dynamics emerged as a major theme from participants' discussions of their academic experiences and experiential opportunities in the workplace, including internships and co-ops. The prevalence and complexity of gender-related dynamics in participants' experiences and decisions led us to reanalyze gender-related data according to a new research question: What are the gendered academic and workplace experiences of graduating women in engineering?

This study was conducted at a public research institution in the Southeast with a large engineering college that hosts eight engineering departments, including computer science. Consistent with national figures, $20 \%$ of engineering students at this institution are women, with the representation of women varying by department. We collaborated with two engineering faculty and staff members to distribute information about the study via printed flyers at a campus event for women in engineering, and via an email to senior women in engineering to recruit eligible participants. Based on the original study's research questions, eligibility was restricted to female students in the institution's engineering college who were graduating with a bachelor's degree in May 2016 and who had already accepted a job at the time of study recruitment in January 2016, thus excluding students who planned to attend graduate school or who had post-graduate plans other than working full-time. Participants received $\$ 10$ Amazon gift cards for their time. 


\subsection{Sample}

Overall, the sample was comprised of 10 women engineering seniors nearing graduation, which allowed an in-depth understanding of the experiences of participants within a bounded system. Participants were high-achieving academically, with nine of 10 participants having GPAs over 3.0, and five of the 10 with GPAs over 3.5. Further, all participants' resumes contained engineering experiences outside of their classes, including at least one experience of the following: an internship, a co-op, undergraduate research, engineering-specific study abroad, and student and/or professional organizations related to their majors. While internship or co-op experiences were not deemed necessary for participation in the study, nine of 10 participants reported having at least one internship, with most participants completing more than one. Neither internships nor co-ops were required by students' academic programs at this institution, participants sought these experiences voluntarily. Participants reported finding most of these field experiences through the institution's resources, including an online job portal, career fairs, and alumni connections. Participants represented traditionally-aged college students between the ages of 21 and 24, with six participants identifying as White, two as Asian/Asian American, one as African American/Black, and one as biracial. Participant majors are displayed in Table 1. Both the chemical and biomolecular engineering department and the industrial and systems engineering department at the site institution have populations where at least one-third of undergraduate majors are female. All participant names used in this report are pseudonyms.

Table 1. Participants by Majors.

\begin{tabular}{cc}
\hline Pseudonym & Major \\
\hline Kayla & Chemical Engineering \\
Lexie & Chemical Engineering \\
Megan & Chemical Engineering \\
Jiwon & Chemical and Biomolecular Engineering \\
Madu & Chemical and Biomolecular Engineering \\
Whitney & Civil Engineering \\
Alisa & Computer Science \\
Emily & Industrial and Systems Engineering \\
Faith & Industrial and Systems Engineering \\
Jessica & Industrial and Systems Engineering \\
\hline
\end{tabular}

\subsection{Data Collection and Analysis}

All participants completed a 30 to 60-min semi-structured interview, a demographic survey, and submitted a copy of their resume and a job description for the respective roles they had accepted. According to the original research questions, the interview protocol focused on participants' early engineering interests, as well as experiences and decisions related to college choice, major selection, involvement in college, and their job search. Four questions were asked specifically regarding gender dynamics: "How would you describe the gender distribution of your engineering faculty members?" "Do you think the experience of female students is different from the experience of male students in the engineering college and in your major?" If participant completed an internship: "What was the gender distribution of your colleagues and/or fellow interns?" Lastly, "What impact, if any, do you anticipate that your gender will have on your experience in your first job?" In addition to these prompts, participants shared a host of gender-related experiences and reflections in response to a range of questions asked.

Interviews were transcribed and, consistent with case study methods, we used open and axial coding procedures such as direct categorical aggregation and interpretation to look for patterns, and naturalistic generalizations to analyze data and identify themes (Merriam 2009; Stake 2005). First, transcripts were reviewed for any comments related to gender experiences, as per the study's research question. Second, we conducted open coding by reviewing gender-related comments within each 
transcript line-by-line and assigning codes to significant words and phrases (Johnson and Christensen 2000; Merriam 2009), with 203 initial codes generated during this process. Third, initial codes were organized into labels and chunked together to develop axial, or analytical codes to identify emerging themes and subthemes based on related codes within each participant's transcript and then across transcripts to best represent shared participant experiences (Stake 2005).

\subsection{Data Trustworthiness}

We used multiple strategies to build validity and trustworthiness of findings. After interviews were complete, transcripts were shared with participants for their review via a member checking process. During and after interviews, we wrote analytic memos, notes containing preliminary analysis and interpretation, to track notable comments, ideas, and themes from each interview as well as those emerging across participants (Johnson and Christensen 2000; Merriam 2009; Yin 2014). Data from the demographic surveys and submitted documents were used to triangulate interview data to increase internal validity (Yin 2014). All data and researcher notes were saved to a centralized database for organization and collaboration within the research team (Yin 2014). In the presentation of results, rich description is used, as is characteristic of case study research (Merriam 2009). Rich, thick description, is the "complete and literal description of the incident or entity" (Merriam 1998, p. 29) and is used in the form of emic codes, or the use of participants' words to represent themes, the inclusion of participant quotes, and detail related to the research setting to allow the reader to assess the transferability of results to alternative settings (Fetterman 2008; Guba and Lincoln 1994; Lincoln and Guba 1985; Merriam 1998, 2009).

\subsection{Limitations}

Despite the actions taken to maximize trustworthiness, the present study has several limitations. First, case study research is conducted to gain a deep understanding of a particular sample, thus limiting generalizability of findings (Merriam 1998). In the present study, the sample is small, limited to one institution, and recruiting criteria included only participants who had accepted jobs by early spring semester prior to their graduation, perhaps making them inherently different from other female engineering students. The sample only includes participants who persisted through their undergraduate engineering degrees, excluding women who may have left engineering due in part to negative experiences or perceptions of fit. Additionally, our sample is comprised mostly of students in the chemical and biomolecular engineering and industrial and systems engineering departments, two departments with a higher representation of women in comparison to other engineering majors. Based on the persisting sample and the distribution of majors that they represent, it is likely that the gender-related experiences of participants in the present study may underrepresent negative experiences of undergraduate women in engineering.

\section{Results}

\subsection{Academic Environments}

Participants shared a wide range of experiences related to gender dynamics in their engineering academic settings. While three participants described feeling equal or even advantaged compared to their male peers, all participants also reported experiences of differential treatment in their courses and group projects. While examples of outright sexism were relatively rare in these settings, experiences of implicit bias were pervasive. Within this theme, we identified three subthemes: "I don't think my education is any different," "Being underestimated constantly," and "You don't want to be seen as getting advantages." 


\subsection{1. "I Don't Think My Education is Any Different"}

Three participants in majors with more equal gender distributions tended to perceive and state that they had the same education and experiences as their male peers. Yet, these comments were almost always immediately followed up with examples of implicit bias, suggesting the pervasiveness of such experiences and participants' tendency to overlook or become accustomed to this dynamic:

In the classroom there's less females than there are males. But I don't think my education is any different than a male's education. I think sometimes boys will be boys and they're like "oh, and I mean you're not gonna want to do a manufacturing job. You're not gonna want to do that. That's more of a male's job." Obviously it's not. (Jessica)

Faith described that her experience was probably the "same exact" as the experiences of her male classmates, then immediately shared a story of a male classmate who was surprised to find out that she was an engineering major, despite their mutual enrollment in the same engineering class. Lexie shared a similar perspective, although she then shared a story where her gender identity received great attention from an engineer who visited her professional development class, implying that it's "not a normal sort of thing." While these three participants described feeling that their educational experiences were the same as those of male peers, immediate follow-up examples suggested that gender did influence participants' interactions in academic settings and that these perceptions of "same exact" experiences are contextualized in a setting where differential treatment was somewhat expected or common and, thus, overlooked. Neither Whitney nor Alisa, in the majors where gender was most skewed, made comments that fit this theme.

\subsection{2. "Being Underestimated Constantly"}

Interactions with male peers, particularly through group projects were some of the most common contexts for experiences of gendered dynamics in academia. Participants were often the only women in their groups and reported experiences of male teammates ignoring or challenging their contributions, placing far greater value on the opinions and work of other males, neglecting to communicate with them, and even making directly disparaging comments. Emily described, "I guess one thing that you have to deal with is being underestimated constantly." To counteract feeling underestimated, women shared instances of going above and beyond to support their contributions, a burden that was frustrating and demotivating. Alisa discussed a project where male peers erased her work without her consent, assuming it to be incorrect. After advocating for her contributions, her peers checked her work with their professor, restoring it only after the professor confirmed its accuracy. Alisa reflected, "It's incredibly frustrating that they won't believe you. We have to perform to a higher standard."

Several women noted that the tone of these interactions was often negative:

One time I was explaining to everyone how I thought this thing was, and then this guy stood up and he said, "I think you're right, but your reasoning is wrong" ... Honestly, if it's another guy, he would be like, "Okay, it's fine" but if it's another girl, then he would try to be condescending about it. (Madu)

Kayla agreed that women were treated differently in these settings: "the first thing you hear always, if someone is unhappy with a female group member is, 'this girl in my group is a bitch.' And I don't think I've ever heard the male equivalent of that."

In addition to being underestimated or challenged, especially in the context of technical contributions, some women were left out or ignored entirely. Accustomed to contributing significantly to group work, Megan asked, "how do you deal with somebody that is doing too much work and not letting you participate, especially when you are being present and communicating?" For a group project where she was the only woman, Megan was left out of all communication of plans and progress on the technical parts of the project. When she addressed the issue with her teammates and no changes 
were made, Megan decided to leave the group: "I'll be damned if I'm going to be working on the poster and hadn't actually done any engineering."

Negative perceptions that male engineering students held about their female peers wore off on female students' interactions with one another as well. Alisa noticed herself judging female peers who were particularly feminine or who did not portray themselves as intellectual: "Sometimes the guys will be like, 'Oh, my gosh. She's such an airhead,' or something ... . You start hating on other women for their choices." Alisa attempted to distance herself from negative gender stereotypes as a way to receive respect and to better fit in with male peers. Alisa did not like feeling judgmental toward other women, yet found this to be an unconscious defensive reaction to the dynamic. In a similar vein, Faith also encountered "a negative stereotype" derived from male peers that impacted perceptions and dynamics between female students:

I had a girl tell me, "I thought you were going to be one of those of those girls that just hangs out with a bunch of guys and gets all their answers" ... I've heard guys say that. "Oh, she hangs out with all guys. She gets all the answers from them."

Faith saw this competitive and demeaning stereotype to be "detrimental" to the overall image of women in the engineering college, and to peer dynamics between women and men alike.

\subsection{3. "You Don't Want to Be Seen as Getting Advantages"}

Even in the context of negative dynamics in academic settings, women also frequently mentioned gender-specific "advantages," including access to gender-based student organizations, unique networking opportunities, targeted campus resources, and perceived preferred access to applied experiences such as internships and research opportunities. While women tended to describe the availability of these resources and opportunities positively, they were often hesitant to engage for fear of being seen as "weak," or as though they were receiving extra benefits due solely to their gender.

Although the site institution offered multiple STEM organizations for women, only one participant, Alisa, was an active member. Notably, Alisa was the only participant who studied computer science, the most male-dominated department in the engineering college represented in our sample. Alisa described one experience she had while trying to recruit new members:

I was doing recruiting ... we had to talk to the students and then pass a sign-out sheet, and there was a group of girls sitting together and one of them wanted to sign up, but the other one was like, "No. don't do it." So, there's this like-it's just so frustrating 'cause it's really seen as like a sign of weakness or that they're giving something up because there is kind of a mentality that sometimes a girl only got the job because she's a girl. So, a lot of women feel like if you're in [a women's organization] then you get some sort of advantages ... you don't want to be seen as getting advantages.

Faith, like most participants, was not formally affiliated with any women's STEM organizations but occasionally participated in women's engineering events, primarily to network with employers or to serve as an ambassador for prospective female students. She described:

I think my experience and what I've been exposed to and the opportunities that I have been exactly the same. Honestly even more because they do have a lot of women in engineering events ... I have a lot of guy friends who are like, "Wait I can't come to that?" I'm like, "Sorry."

Despite most participants' comments about perceptions of advantages, one participant was actively involved in a professional organization related to her racial identity rather than her gender, and attributed this group to her decision to stay in engineering, both through college and into her first job. This participant did not mention any concerns related to perceptions of her participation in this organization, instead reporting a highly positive experience with her involvement in this group. 
Beyond the presence of targeted campus organizations and events, women acknowledged that there was a general belief, especially among men, that women were at an advantage in the classroom and in getting jobs. Emily stated that men seemed to attribute women's successes to their gender: "Guys always complain about not getting things and girls getting them because we're girls. And it's like, 'no, I have better grades than you, so I'm sorry.'" Although the women in our sample had strong resumes with predominantly high GPAs and well-rounded engineering and extracurricular experiences, several participants mentioned that they too suspected that their gender, in addition to their accomplishments, might have helped them gain access to internships and jobs: "a lot of places are conscious of that sort of thing now and are trying to get women in. I think it's almost a - she hits a diversity check mark" (Megan).

\subsection{Workplace Environments}

While women described examples of bias in academic settings, experiences of outright sexism, including sexual harassment, were more prevalent in their accounts of internships and co-ops. Although participants were accustomed to being gender minorities in academic settings, their female identity was even rarer in the workplace. Participants were frequently one of few women in work environments, especially among engineers. With this skew, experiences of bias and sexism were common. Within this theme we identified three subthemes: "Oh, you're a girl," "There's a lot of sexism," and Benefits of "girl power."

\subsection{1. “Oh, You're a Girl”}

Participants consistently noted the impact of their gender on first impressions in the workplace, where gender seemed to centrally define their identity in initial encounters and interactions with new colleagues. Gender-based first impressions with male colleagues were perceived as unwelcoming and accompanied by negative presumptions of participants' engineering competency. Not only was gender immediately noticed by coworkers, but often explicitly pointed out: "definitely whenever you walk into an internship as a girl they say something about it" (Emily). Emily described, "You walk in the factory and you obviously don't belong there, so they gawk at you and stuff." Jiwon also noticed this reaction to her gender, which contrasted her experience in school:

Sometimes when I go to industry, like when I go to a co-op or intern, people just made comments, says like, “Oh, you're a girl. You don't know that stuff. You can't--" Those little stuff bothered me, but at school, I never really experienced that.

Due to these judgments, participants were highly conscious of their actions and dress, often attempting to minimize their feminine image to reduce negative perceptions. Working at a computer networking company with very few women, Alisa paid close attention to her appearance: “There's this feeling sometimes that if you're an engineer, you can't dress pretty and you can't be interested in girly things because, like, god forbid, some guys might not take you seriously 'cause you're wearing a dress."

At Kayla's internship experience at a chemical plant, female interns were asked to meet with the company's sole female manager:

She got the girl interns together and told us that some of our bosses that were men expressed an interest in her talking to us about our behaviors and who we interacted with and being careful about how we dressed and not wearing makeup to work.

Kayla went on, describing the conversation: "she was like, 'There's no reason to wear makeup to work anyway, people are only going to catcall you when you walk from building to building for meetings.'" Instead of addressing sexist behaviors to provide an inclusive workplace, this organization made it clear that women should adapt to the male-dominated environment in their behavior and dress. Further, sexual harassment and other inappropriate behaviors were misattributed to female interns' dress and interactions, with no repercussions for perpetrators. 
While participants' intentions in participating in internship experiences were to gain field experience and contribute to an organization's mission, women's work went far beyond these basic goals. In addition to performing the expected work, women bore the burden of mitigating negative perceptions and interactions to effectively navigate frequently unwelcoming cultures. To illustrate women's attempts to overcome negative first impressions and assumptions about their ability, Emily shared an anecdote about the moment where she gained credibility at her internship. Her office had received new chairs, and hers was the only one that had not been put together. Emily described putting the chair together herself, "It was literally like put it on here, screw this ... they thought that it was amazing." Emily described:

I think that they initially underestimate you and they respect you more even if I did the same thing as a boy ... they think I accomplish more because I am inherently unable to do it because I'm a girl or something like that.

Women participants often entered male-dominated workplaces at a disadvantage, immediately faced with gender stereotypes and assumptions of inability that affected ongoing interactions. The burden of managing these perceptions while adjusting to new settings and responsibilities served as an extra barrier to establishing fit and credibility in these roles.

\subsection{2. "There's a Lot of Sexism"}

Despite attempting to fit in and prove themselves as engineers, participants often experienced and witnessed sexist and harassing comments and behaviors at their workplaces. Megan described hearing unprovoked comments about her appearance: "In my internship ... one guy said, 'she's pretty enough, someone will marry her' ... That was just the male environment." At her first internship, Kayla's boss openly berated two pregnant employees for the expected impact of their pregnancies on their work schedule. Sexual harassment claims were filed by one staff member and Kayla stopped interning at that organization due to the hostile environment. At her second internship, Kayla described that "hazing" new staff members was common; she was locked out of the only women's restroom in her building by male colleagues for the first week of work and was intentionally given wrong directions to meetings for the first month. When asked about the perceived role of her gender in the hazing, Kayla explained that these behaviors were "normal" for new employees and interns to experience, but that women were especially likely targets. Summing up her second internship, Kayla described, "There's a lot of sexism, and a lot of long hours." Notably, Kayla was the only participant who accepted a job outside of engineering, as she had instead searched for environments with a more equal gender balance.

Unfortunately, participants often described experiences of sexually inappropriate behaviors. Emily's experience of being "gawked at" in a male-dominated work setting was mentioned by a few participants, especially within manufacturing and construction settings. Kayla shared that her coworkers would offer her rides between buildings at the large plant, "but then sometimes when you're in the car, they'll start making really awkward, uncomfortable comments." Sexist comments and behaviors were not only uncomfortable, but they also affected participants' ability to perform in their work environments. As Whitney shared:

It was a little weird because the guys make jokes and things like that. And even just on the construction site being a female, you get some comments here and there, and it's like, really? I'm just trying to do my job.

\subsubsection{Benefits of "Girl Power"}

In the relatively rare occasions where women were well-represented in engineering workplace settings, participants spoke positively about these situations. Jessica was the only participant to discuss an internship setting where there was an equal representation of males and females. This gender balance was important to her internship search and she ultimately accepted a full-time offer at the same company at the conclusion of the experience. Jessica shared that female interns "stuck together," 
discussing career goals and plans to balance work and have a family, while paying close attention to the company's treatment of women and their representation within leadership roles. Similarly, Whitney shared an experience with an engineering project team during her internship that was predominantly female, a rarity. Being a part of a group of women engineers allowed for conversation about the experience: "Having females to talk with and stuff like that, that was awesome. I remember one night after work, they invited me to get drinks and stuff like that ... we just kind of talked about females in the industry." Whitney contrasted this experience with her next project team in the same internship, an "opposite experience" where she was the only female engineer on site. As Whitney summed:

I think you benefit from seeing people who look like you around you, even if it's just a male or female. Because I walk into a room of females, I'm like, "Oh yeah, girl power." Like, "We in here, we doing it."

\section{Discussion}

The present study provides continued evidence of power disparities, as well as examples of implicit bias, sexism, and sexual harassment experienced by women engineering students in both academic and workplace settings. While a growing body of literature focuses on the experiences of female engineering students in academic or work settings, the present study is particularly novel in its deep examination of gender dynamics within two environments where undergraduate students are most likely to gain field-relevant knowledge and career experiences. Using a feminist lens to understand women's dual experiences of these environments, feminist standpoint theory allowed the placement of gender at the center of analysis to critically reflect on the ways in which power dynamics and male privilege were evident in these spaces.

Results support research that shows the existence of bias in both academic and workplace settings. In addition, our findings contribute to the larger body of literature by providing insights regarding these respective environments within the same sample, which offers a distinct opportunity for comparison. The present study is unique in its contribution to the understanding of women college students in the workplace, as the literature on women in engineering workplaces largely focuses on women who have completed their degrees and entered jobs in the field rather than the internship and co-op experiences of women students making critical decisions about their career interests and pathways. The heightened sexism experienced by women in work environments compared to academic environments is a critical finding with important implications for the persistence of women in engineering, both through college and into their careers.

During their collegiate years, students are often assessing their interests and abilities, trying new subjects and fields, exploring career options, and building a foundation of knowledge that will inform their career ideas and decisions after college. Better understanding the environments that shape these experiences is critical to increasing the retention and persistence of women engineers. The present research demonstrates that while experiences of gender bias are present for women in academic settings on college campuses, experiences of bias and sexism tend to be not only present, but further amplified in male-dominated workplace settings where students gain engineering field experiences through internships and co-ops. Findings show that women regularly enter and navigate uncomfortable, and sometimes hostile, engineering environments where their technical skills and accomplishments are overlooked and where their gender prominently affects first impressions and ongoing interactions. Further, women participants were frequent targets of biased, sexist, and sexually harassing behaviors and comments. Gender representation seemed to play an important role across these environments, the spaces least friendly to women were among the most male-dominated, whereas the most welcoming and supportive spaces for women were well-populated with other women.

With the growing emphasis on increasing the representation of women in STEM fields, more opportunities are available to support women's engagement in these settings now than ever before (Hughes 2015; Hyllegard et al. 2017; National Science Board 2016; Office of Science and Technology Policy 2016). However, despite the increased availability of programs and opportunities, significant 
cultural barriers remain. Despite reporting specific examples and regular occurrences of sexism and implicit bias in class settings and group interactions, some participants still perceived their academic experiences to be equal to those of male peers. This finding is consistent with research that suggests that such differentiation is perceived by women in male-dominated environments as natural or expected, particularly as some women adapt to manage stereotypes and to better fit in in an attempt to persist (Amon 2017; Buse et al. 2013; Fouad et al. 2016; Hewlett et al. 2008; McPherson 2017; Neumann et al. 2016; Powell and Sang 2015). Alisa and Faith both described these adapting behaviors in their examples of female engineering students distancing themselves from other women and feminine stereotypes in order to gain acceptance. Therefore, instead of addressing the issues inherent in these perceptions and actions, the problematic cultural norms are both accepted and perpetuated.

The reported availability of "advantages" accessible to women engineering students further emphasizes the gap between structural and cultural acceptance. While participants were largely aware of campus resources available to women engineers and recognized these resources as supportive toward the growth and success of women in engineering, they tended to avoid them based on implicit cultural expectations. Participants described male peers expressing frustration at women's perceived advantages in obtaining internship and job opportunities as a result of access to exclusive resources and diversity-focused hiring. Because of this perception, most women carefully restricted their own engagement with these resources in fear of appearing less self-sufficient or capable than their peers in order to prove their engineering abilities over a more visible characteristic, their gender.

By nature of the sample members' persistence, high level of academic achievement and extracurricular involvement, or perhaps by the more balanced gender ratios in most of the participants' majors, participants in the present sample who were not involved in women's STEM organizations likely formed their own informal support systems (Hughes 2010). Alisa's description of recruiting efforts for her organization suggests that the stigmatization of women's STEM organizations detracts from women's participation in these groups and, as a result, their access to resources specifically designed to support their success. While many women may succeed without participating in these organizations and related programs that are found to provide a positive community s, greater self-efficacy, and a reinforced engineering identity, research consistently suggests the benefits of support systems, as well as the detrimental effects on persistence that a lack of support can have for women in STEM (Beyer 2014; Gayles and Ampaw 2016; Hughes 2010; Kezar and Holcombe 2017; Litzler and Young 2012; Marra et al. 2009; Neumann et al. 2016; Ro 2011). Thus, the avoidance of available resources, particularly due to stigma, could be detrimental, especially for those who do not access, or who are unable to access, informal support on their own.

It should be noted that the intersection of race, gender, and engineering-related experiences are not explored in-depth in this article, as racial identity was not central to the present research question. However, one participant's experience in organizational affiliation based on racial identity warrants additional discussion related to this dynamic. As mentioned in the results, one of the women of color in our study participated in an engineering organization for students who shared her racial identity. This participant was involved in this organization without expressing any concern about the external perception of her involvement, first joining the group to "surround myself with like-minded people," and quickly ascending into leadership positions. She described this experience only in positive terms, attributing her involvement in this organization to her receipt of academic and moral support, her professional network, and to her decision to stay in engineering post-college.

Because this is only one participant's experience and because racial identity and the intersection of multiple identities were not explored deeply in the present study, it is difficult to assess why this participant viewed her experience of joining this organization without the concerns expressed by her peers regarding external perceptions and assumptions of merit or unfair advantage. Differential experiences could be attributed to the participant herself, the organization itself, or broader differences in cultural acceptance of participation in some types of identity-based STEM organization in comparison to others. At the site institution for this study, while $20 \%$ of engineering undergraduate 
students are women, only about $8 \%$ of all undergraduate engineering students are international, $7 \%$ are Asian American and $4 \%$ are African American. The significant underrepresentation of racial minorities could also contribute to the importance of certain identity-based communities, or acceptance for such organizations. This finding underscores the importance of intersectionality in understanding how individuals who hold more than one marginalized identity navigate oppressive environments (Crenshaw 1991). Regardless of the explanation, the participant's positive experience suggests the benefits of identity-based professional and student organizations, including a supportive network of peers, alumni, and access to other professionals with shared identities and interests, as well as leadership and professional opportunities and the reinforcement of an engineering identity.

The self-mitigating behaviors of some participants restricting their engagement with certain resources is suggestive of the salience of gender identities for participants and related cultural barriers that are highly consistent with the pollution theory of discrimination (Goldin 2014). Participants' peers and colleagues held negative assumptions about their skills and abilities on the basis of stereotypes, ignoring or overlooking women's technical abilities. Our sample was particularly high-achieving based on GPA, campus involvement, and both curricular and extracurricular engagement, yet their skills and merit were underestimated across settings, with accomplishments attributed primarily to the availability of gender-specific resources and perceived advantages. This perception led to exclusion from opportunities to build technical skills or knowledge in academic settings (e.g., Megan's exclusion from her group), and in workplace settings (e.g., Jiwon's account of colleagues who would not teach her). Thus, despite participants' structural access to environments that contained learning and skill-building opportunities, limitations were placed on their engagement and access to knowledge and networks. The perception that women did not possess the same engineering skills as their male peers led to limitations in access to technical training, providing unequal opportunities for growth and engagement-a self-perpetuating cycle with negative implications for women's engineering growth and career progression (Heilman 2012; Powell et al. 2011).

Findings suggest that the workplaces where participants conducted internships were male-dominated spaces that were unsupportive of women at best, and hostile and discriminatory at worst. Women in these spaces often faced a paradoxical situation where they were expected to de-emphasize feminine appearances and behaviors, but were also criticized for behaving similarly to male colleagues (Powell et al. 2011). Among participants, perceptions and expectations related to dress and appearance, especially as described by Alisa and Kayla, were an apparent manifestation of this dynamic. The implicit and explicit expectations of women to avoid appearing feminine and to monitor not only the content of their interactions, but also who they engaged with at all, demonstrates additional further biased cultural barriers (Amon 2017; Rhoton 2011). Instead of workplace environments adjusting their cultures to welcome and support the growing diversity of their employees, women were expected to adjust their own behaviors to fit sexist cultural norms.

Despite efforts to adapt to these environments, de-emphasizing femininity, and striving towards displaying an engineering identity and a cultural fit, women in the present study were still subjected to sexism and sexual harassment. Whitney's comment about "just trying to do her job" in an environment where she was the target of sexually inappropriate comments is indicative of the powerless feeling that participants experienced in response to these dynamics. Notably, participants in internship positions faced not only the various biases that have been documented among full-time female engineers, but from a hierarchical standpoint, undergraduate students in temporary employment arrangements such as internships or co-ops often do not have the same benefits and protections of full-time employees, leaving these women with even less power than their full-time counterparts.

\subsection{Implications for Practice}

Existing research suggests a host of recommendations for creating more inclusive, supportive, and gender-balanced academic environments, including increasing the number of female faculty in engineering, providing opportunities for women's leadership and involvement in engineering 
departments, and building awareness of bias through training for faculty and students alike (Corbett and Hill 2015; Deemer 2015; Smith and Gayles 2017). Given the continued underrepresentation of women in engineering and the prevalence of bias, systems designed to support women's representation and persistence, and to increase a broader awareness of equity issues in the field continue to be necessary. However, results from the present study suggest that even with the existence of these systems, cultural barriers remain, and women may be hesitant to use the resources available to them.

Consistent with feminist theory, the lack of understanding of the purpose and necessity of these organizations from men is a symptom of a larger problem of power dynamics in these social locations. This oppressive dynamic fails to recognize the historical and present-day challenges that women face in gaining equitable access to opportunities and advancement in fields like engineering. Thus, we recommend the continuation of services and organizations that serve to promote the retention and success of women in science and engineering fields. However, the overall culture regarding these organizations must be proactively addressed. Diversity-positive environments require involvement and commitment from top administrators, department leaders, as well as the backing of a unified campus community and a sustained diverse workforce (Anicha et al. 2017; Kezar and Holcombe 2017; Sax et al. 2017). Understanding campus climate through the use of surveys and data through institutional research offices can help to identify current barriers and design effective interventions to counteract sexist behaviors and systemic injustices that contribute to the underrepresentation of women in these settings (Anicha et al. 2017). A unified message from faculty members and administration regarding equity in educational and workplace settings is an important concept that should be better communicated and modeled by university leadership to promote broader support and demystify the purpose of such organizations across college campuses.

In the workplace, even more progress is needed to provide a supportive environment for women in engineering, especially for interns and other early-career engineers based on patterns of persistence (Kahn and Ginther 2015). The most positive internship experiences described by our participants featured the presence of other females in the workplace, particularly in engineering roles. The presence of women engineers provided a comfortable space to discuss and explore identity, professional opportunities, and evaluate the company's environment and pathways for upward mobility. Companies hiring interns should think critically about the experiences of employees at their organizations and should strategize ways to provide access to supervisors and other informal and formal mentors representing a wide range of identities, including women and people of color. In the event that a company does not yet have this representation, employees and interns should be given resources and recommendations for connecting to local professional organizations in their field, and the time and support to do so.

In addition to serving as resources for other women, the increased presence of underrepresented identities in engineering companies and organizations is critical to building cultures that promote learning about other ways of being, increasing the number of diverse employees to reduce preconceptions and stereotypes. Proactive steps to increase the representation of women at all levels within engineering organizations can reduce biases that stem from ill-informed judgments that contribute to biased and sexist behaviors (Greenwald and Krieger 2006; Tatum 1997). One way to increase the persistence and advancement of women is through targeted leadership development programs. Such programs should promote the exploration and building of engineering and leadership identities, as subtle forms of discrimination undermine the abilities of underrepresented groups to construct and internalize these identities. However, by reinforcing engineering and leadership identities, we can hope for greater self-efficacy, satisfaction, and persistence of women in these fields (Buse et al. 2013; Hatmaker 2013).

In addition to providing support systems, it is also critical that organizational policies are reviewed and updated to protect the rights and experiences of all employees, including interns. In order to create more equal and supportive environments, companies must ensure that their policies, particularly on topics such as dress code and employee conduct, reflect changing workplace dynamics and that 
underrepresented groups and identities are protected from bias, discrimination, and sexual harassment. Company leadership should review and adjust their policies in collaboration with external consultants or internal experts in equal opportunity and diversity. Further, such policies, as well as employee resources, must be communicated by organizational leadership to supervisors and all staff members, including interns, as part of an orientation process, and in regular intervals. Regular communication and training will help to build a greater awareness of standards and expectations, as well as access to available resources.

Beyond the implications for and responsibilities of employers related to providing a safe and supportive work environment for employees and interns of diverse identities, colleges need to consider their role in this relationship. Although internships and co-ops were not required by the present institution, many participants secured these opportunities by using institutional resources and connections. While colleges with credit-bearing or mandated field experiences should have specific policies in place articulating their expectations to employers and companies in cooperative agreements, other programs or students may not have access to the same protections. All institutions that support the recruiting of their students through campus resources should establish policies and communicate expectations with employers regarding the hiring process, as well as the experience itself. Further, institutions must provide an opportunity for students to provide feedback about their field experiences with employers, perhaps through creating a centralized system or process through career services offices to collect and identify concerns and trends related to identity-based discrimination or harassment.

One of the primary benefits of having students in internship and co-op positions is their potential contributions to the workplace, including bringing in new perspectives and applying fresh technical training. Organizations should consider a variety of ways that students in these roles could have a voice in their companies, including displaying their skills. As women's gender identity tended to define new colleagues' impressions and assumptions of participants' abilities, companies may consider ways for interns to share their prior accomplishments and current skills with colleagues and supervisors when they are first introduced to their roles to build credibility earlier in their internships through presentations or other venues of communication. Further, at the conclusion of these experiences, companies may consider a way for students to share their work, perhaps in the form of a community lunch or showcase event to help students build their communication skills while reminding staff of their progress and value to the organization. Lastly, companies should provide ways for students to provide honest feedback about their experiences, whether through an evaluation or exit interview. Colleges that collect this feedback should also establish a mechanism for sharing anonymous data with employer partners.

\subsection{Future Research}

The findings from this study indicate several potential directions for further research and exploration. By nature of our original study's aims, the present sample is small and limited to women engineering students who have persisted in their majors throughout college, and who had received job offers four months ahead of their college graduation. Thus, the sample does not include women who may have switched majors out of engineering, who may not have had the same level of academic success and extracurricular engagement that contributed to early job searching and opportunities for the current sample, nor those planning to pursue graduate education following the completion of their bachelor's degree. Studying a larger sample of undergraduate women engineers who represent a wider range of engineering majors at various stages in their collegiate careers and those with a greater variety of post-college plans would help create a more nuanced understanding of the gender-related and overall experiences of these students on campus and in the workplace.

The complexity of the findings and existing research related to participation in women's student and professional organizations warrants additional examination. According to Hughes (2010), women who do not participate in women's organizations but who do persist in STEM majors tend to find 
support systems elsewhere, as many of our participants did. In their interviews, many described the positive experiences and support gained from peers, faculty and staff members, colleagues, alumni, and other organizations. Further research investigating the nature of these support systems and how women build them, perhaps comparing those who do and do not participate in women's STEM organizations, could provide important insight into the benefit of these organizations, as well as provide guidance for future students seeking to find support. The stigma associated with women's STEM organizations should be challenged because it is clear from our findings that women value and thrive with support systems. The notion that social and cultural barriers restrict women from taking advantage of organized systems designed to bolster their success is unfortunate, particularly in the context of research showing the detrimental effects of a lack of support on women's persistence. Future research might therefore also explore ways to alleviate the stigmatization of support for women and other students of underrepresented identities in the interest of continued growth and persistence of these populations in engineering fields.

In addition, future research should further explore the intersectionality of women in engineering, particularly the multiple marginalized identities and systems of power experienced by women of color within STEM environments (Johnson 2011; Wijeyesinghe and Jones 2014). While exploring the influence of multiple underrepresented identities was outside the scope of the present study, some findings, particularly the influence and perception of participating in identity-based student organizations, may vary in transferability by women's diverse identities and experiences. In addition to further exploring support systems and participation in gender-based organizations, future research can take a similar approach specifically with women of color. Those with multiple marginal identities are often excluded from research, resulting in a limited understanding of the ways in which their experiences may differ from individuals whose identities are better represented in research. In order to increase the representation of women in engineering and the creation of policies and practices that properly support all women in engineering, additional attention to these underrepresented populations is critical.

Lastly, studying workplace environments using methodologies such as ethnography, for example, is recommended to gain a deeper understanding of the culture and climate of these spaces. Internships, cooperative education, and other career-related experiences are becoming more common for college students and can have critical implications for students' persistence and goals, and further research will provide a greater understanding of these dynamics, as well as opportunities for growth and improvement.

\section{Conclusions}

Our findings illustrate the continued structural and sociocultural challenges in academic and workplace settings that negatively contribute to women's experiences in engineering. In academia, women experienced implicit bias in a variety of interactions and environments, especially from male peers in team projects where women's contributions were overlooked. Although specific campus organizations and networking opportunities were available for women in engineering, participants tended not to participate, in part to mitigate perceptions of advantages based on gender. In participant experiences within the workplace, gender bias, including sexism and sexual harassment, were amplified and the representation of women was more imbalanced. Participants faced immediate perceptual barriers based on their gender, were consistently underestimated, and frequently experienced inappropriate comments and behaviors from colleagues that made them uncomfortable and detracted from their ability to effectively fit in and receive maximal benefit from these experiences.

In both settings, power dynamics shaped the experiences of women in engineering. Women were expected to adapt to male-dominated, unfriendly, and, often, sexist environments in both academia and in the workplace. Consistent with feminist standpoint theory, featuring women's accounts of their respective experiences gives important insight into gender dynamics in two settings that are important to the retention of women into the engineering workforce, a goal that is not only critical for gender 
equity and opportunity, but is also for meeting national goals and needs. More work must be done within academic and workplace environments to increase awareness of these issues, decrease barriers for women and other underrepresented groups to these fields, and to proactively support their access, persistence, and success.

Author Contributions: Smith conceived the original case study and both authors conducted interviews and collected data. Gayles conceptualized the present study and both authors developed the study's research question. Smith led data analysis. Both authors contributed to writing and editing all sections of the paper.

Conflicts of Interest: The authors declare no conflict of interest.

\section{References}

Amelink, Catherine T., and Elizabeth G. Creamer. 2010. Gender differences in elements of the undergraduate experience that influence satisfaction with the engineering major and the intent to pursue engineering as a career. Journal of Engineering Education 99: 81-92. [CrossRef]

Amon, Mary J. 2017. Looking through the glass ceiling: A qualitative study of STEM women's career narratives. Frontiers in Psychology 8: 1-10. [CrossRef] [PubMed]

Anicha, Cali L., Canan Bilen-Green, Ann Burnett, Karen Froelich, and Sandra Holbrook. 2017. Institutional transformation toward a diversity-positive campus culture. Journal of Women Minorities in Science and Engineering 23: 147-67. [CrossRef]

Beyer, Sylvia. 2008. Predictors of female and male compute science students' grades. Journal of Women and Minorities in Science and Engineering 14: 377-409. [CrossRef]

Beyer, Sylvia. 2014. Why are women underrepresented in Computer Science? Gender differences in stereotypes, self-efficacy, values, and interests and predictors of future CS course-taking and grades. Computer Science Education 24: 153-92. [CrossRef]

Beyer, Sylvia. 2016. Low awareness of occupational segregation and the gender gap: No changes over a 16-year span. Current Psychology, 1-17. [CrossRef]

Blair-Loy, Mary. 2013. The Persistence of Male Power and Prestige in the Professions: Report on the Professions of Law, Medicine, and Science and Engineering. New York: Center for Research on Gender in the Professions (CRGP), March.

Buse, Kathleen, Diana Bilimoria, and Sheri Perelli. 2013. Why they stay: Women persisting in US engineering careers. Career Development and International 18: 139-54. [CrossRef]

Canney, Nathan E., and Angela R. Bielefeldt. 2015. Gender differences in the social responsibility attitudes of engineering students and how they change over time. Journal of Women Minorities in Science and Engineering 21: 215-37. [CrossRef]

Cha, Youngjoon. 2013. Overwork and the persistence of gender segregation in occupations. Gender and Society 27: 158-84. [CrossRef]

Chamberlain, Lindsey J., Martha Crowley, Daniel Tope, and Randy Hodson. 2008. Sexual harassment in organizational Context. Work Occupation 35: 262-95. [CrossRef]

Chen, Xianglei, and Thomas Weko. 2009. Students Who Study Science, Technology, Engineering, and Mathematics (STEM) in Postsecondary Education. U.S. Department of Education NCES 2009-161; July. Available online: http:/ /nces.ed.gov/pubs2009/2009161.pdf (accessed on 9 January 2018).

Corbett, Christianne, and Catherine Hill. 2015. Solving the Equation. Washington: American Association of Women, Available online: http://www.aauw.org/aauw_check/pdf_download/show_pdf.php?file=solvingthe-equation (accessed on 9 January 2018).

Crenshaw, Kimberle. 1991. Mapping the margins: Intersectionality, identity politics, and violence against women of color. Stanford Law Review 43: 1241-99. [CrossRef]

Deemer, Eric D. 2015. Women's science major satisfaction: Regulatory focus and the critical mass hypothesis. Journal of Career Development 42: 60-71. [CrossRef]

Eagan, M. Kevin, Jr., Sylvia Hurtado, Mitchell J. Chang, Gina A. Garcia, Felisha A. Herrera, and Juan C. Garibay. 2013. Research programs making a difference in science education: The impact of undergraduate research programs. American Journal Educational Research 50: 683-713. [CrossRef] [PubMed] 
Fetterman, David M. 2008. Emic/etic distinction. In The SAGE Encyclopedia of Qualitative Research Methods. Edited by Lisa Given. Thousand Oaks: Sage.

Flax, Jane. 1996. Women do theory. In Multicultural Experiences, Multicultural Theories. Edited by Mary F. Rogers. New York: McGraw-Hill, pp. 17-20.

Fouad, Nadya A., Romilia Singh, Kevin Cappaert, Wen-Hsin Chang, and Min Wan. 2016. Comparison of women engineers who persist in or depart from engineering. Jouranl of Vocational Behavior 92: 79-93. [CrossRef]

Frehill, Lisa M., Nicole M. DiFabio, and Susan T. Hill. 2008. Confronting the New American Dilemma: Underrepresented Minorities in Engineering: A Data-Based Look at Diversity. White Plains: National Action Council for Minorities in Engineering.

Garibay, Juan C., Bryce E. Hughes, M. Kevin Eagan, and Sylvia Hurtado. 2013. Beyond the Bachelor's: What Influences STEM Post-Baccalaureate Pathways. Paper presented at Association for Institutional Research Annual Forum, Long Beach, CA, USA, May 18-22.

Gayles, Joy G., and Frim Ampaw. 2016. To stay or leave: Factors that impact undergraduate women's persistence in science majors. NASPA Journal about Women in Higher Education 9: 133-51. [CrossRef]

Glick, Peter, and Susan T. Fiske. 2001. An ambivalent alliance. Hostile and benevolent sexism as complementary justifications for gender inequality. American Psychologist 56: 109-18. [CrossRef] [PubMed]

Goldin, Claudia. 2014. A pollution theory of discrimination: Male and female differences in occupations and earnings. In Human Capital Theory: The American Record. Edited by Leah P. Boustan, Carola Frydman and Robert A. Margo. Chicago: University of Chicago Press, pp. 313-48.

Greenwald, Anthony G., and Mahzarin R. Banaji. 1995. Implicit social cognition: Attitudes, self-esteem, and stereotypes. American Psychology Association 102: 4-27. [CrossRef]

Greenwald, Anthony G., and Linda H. Krieger. 2006. Implicit bias: Scientific foundations. California Law Review 94: 945-67. [CrossRef]

Guba, Egon G., and Yvonna S. Lincoln. 1994. Competing paradigms in qualitative research. In Handbook of Qualitative Research. Edited by Norman K. Denzin and Yvonna S. Lincoln. Thousand Oaks: Sage.

Haines, Valerie A., Jean E. Wallace, and M. Elizabeth Cannon. 2001. Exploring the gender gap in engineering: A respecification and test of the hypothesis of cumulative advantages and disadvantages. Journal of Engineering Education 90: 677-84. [CrossRef]

Hall, Roberta M., and Bernice R. Sandler. 1982. The Classroom Climate: A Chilly One for Women? Project on the Status and Education of Women, February; Washington: Association of American Colleges.

Hall, Roberta M., and Bernice R. Sandler. 1984. Out of the Classroom: A Chilly Campus Climate for Women? Project on the Status and Education of Women, October; Washington: Association of American Colleges.

Hatmaker, Deneen M. 2013. Engineering identity: Gender and professional identity negotiation among women engineers. Gender Work Organization 20: 382-96. [CrossRef]

Heilman, Madeline E. 2012. Gender stereotypes and workplace bias. Research Organization Behavior 32: 113-35. [CrossRef]

Hekman, Susan. 1997. Truth and method: Feminist standpoint theory revisited. Signs 22: 341-65. [CrossRef]

Hewlett, Sylvia A. 2008. Off-ramps and on-ramps: Keeping talented women on the road to success. Human Resource Management International Digest 16. [CrossRef]

Hewlett, Sylvia A., Carolyn B. Luce, Lisa J. Servon, Laura Sherbin, Peggy Shiller, Eytan Sosnovich, and Karen Sumberg. 2008. The Athena Factor: Reversing the Brain Drain in Science, Engineering, and Technology. Boston: Harvard Business Review, pp. 1-100.

Hewlett, Sylvia A., Laura Sherbin, Fabiola Dieudonne, Christina Fargnoli, and Catherine Fredman. 2014. Athena Factor 2.0: Accelerating Female Talent in Science, Engineering and Technology. New York: Center for Talent Innovation.

Hong, Lu, and Scott E. Page. 2004. Groups of diverse problem solvers can outperform groups of high-ability problem solvers. Proceedings of the National Academy of Sciences USA 101: 16385-89. [CrossRef] [PubMed]

Hughes, Roxanne M. 2010. Doctoral dissertation, Florida State University. Available online: http:/ / diginole.lib. fsu.edu/islandora/object/fsu\%3A254222 (accessed on 9 January 2018).

Hughes, Roxanne. 2015. An investigation into the longitudinal identify trajectories of women in science, technology, engineering, and mathematics. Journal of Women Minorities in Science and Engineering 21: 181-213. [CrossRef]

Hunt, Jennifer. 2016. Why do women leave science and engineering? ILR Review 69: 199-226. [CrossRef] 
Hunter, Rosemary. 2006. Discrimination in IT organisations. Labour Industry 16: 91-108. [CrossRef]

Hyllegard, Karen H., Karen Rambo-Hernandez, and Jennifer Paff Ogle. 2017. Fashion FUNdamentals: Building middle school girls' self-esteem and interest in STEM. Journal of Women Minorities in Science and Engineering 23: 87-99. [CrossRef]

Ibarra, Herminia. 1999. Professional selves: Experimenting with image and identity in professional adaptation. Administrative Science Quarterly 44: 764-91. [CrossRef]

Intemann, Kristen. 2010. 25 years of feminist empiricism and standpoint theory: Where are we now? Hypatia 25: 778-96. [CrossRef]

Johnson, Dawn R. 2011. Women of color in science, technology, engineering, and mathematics (STEM). New Directions for Institutional Research 152: 75-85. [CrossRef]

Johnson, Burke, and Larry B. Christensen. 2000. Educational Research: Quantitative and Qualitative Approaches. Boston: Allyn and Bacon.

Kahn, Shulamit, and Donna K. Ginther. 2015. Are recent cohorts of women with engineering bachelors less likely to stay in engineering? Frontiers in Psychology 6: 1-15. [CrossRef] [PubMed]

Kezar, Adrianna, and Elizabeth Holcombe. 2017. Creating a Unified Community of Support: Increasing Success for Underrepresented Students in STEM: A Final Report on the CSU STEM Collaboratives Project. Available online: https://pullias.usc.edu/csustemcollab/creating-a-unified-community-ofsupport-increasing-success-for-underrepresented-students-in-stem/ (accessed on 9 January 2018).

Lichtenstein, Gary, Heidi G. Loshbaugh, Brittany Claar, Helen L. Chen, Kristyn Jackson, and Sheri Sheppard. 2009. An engineering major does not (necessarily) an engineer make: Career decision making among undergraduate engineering majors. Journal of Engineering Education 98: 227-34. [CrossRef]

Lincoln, Yvonna S., and Egon G. Guba. 1985. Naturalistic Inquiry. Thousand Oaks: Sage.

Litzler, Elizabeth, and Jacob Young. 2012. Understanding the risk of attrition in undergraduate engineering: Results from the project to assess climate in engineering. Journal of Engineering Education 101: 319-45. [CrossRef]

Marra, Rose M., Kelly A. Rodgers, Demei Shen, and Barbara Bogue. 2009. Women engineering students and self-efficacy: A multi-year, multi-institution study of women engineering student self-efficacy. Journal of Engineering Education 98: 27-38. [CrossRef]

McCann, Carole R., and Seung-kyung Kim. 2017. Feminist Theory Reader: Local and Global Perspectives, 4th ed. New York: Routledge.

McLaughlin, Heather, Christopher Uggen, and Amy Blackstone. 2012. Sexual harassment, workplace authority, and the paradox of power. American Sociological Review 77: 625-47. [CrossRef] [PubMed]

McPherson, Ezella. 2017. Oh you are smart: Young, gifted, African American women in STEM majors. Journal of Women Minorities in Science and Engineering 23: 1-14. [CrossRef]

Merriam, Sharan B. 1998. Qualitative Research and Case Study Applications in Education, 2nd ed. San Francisco: Jossey-Bass.

Merriam, Sharan B. 2009. Qualitative Research: A Guide to Design and Implementation, 3rd ed. San Francisco: Jossey-Bass.

Milkman, Katherine L., Modupe Akinola, and Dolly Chugh. 2015. What happens before? A field experiment exploring how pay and representation differentially shape bias on the pathway into organizations. Journal of Applied Psychology 100: 1678-712. [CrossRef] [PubMed]

Morris, LaDonna K., and Larry G. Daniel. 2008. Perceptions of a chilly climate: Differences in traditional and non-traditional majors for women. Research in Higher Education 49: 256-73. [CrossRef]

Moss-Racusin, Corinne A., John F. Dovidio, Victoria L. Brescoll, Mark J. Graham, and Jo Handelsman. 2012. Science faculty's subtle gender biases favor male students. Proceedings of the National Academy Science USA 109: 16474-79. [CrossRef] [PubMed]

National Research Council and National Academy of Engineering [NRC/NAE]. 2014. Career Choices of Female Engineers: A Summary of a Workshop. Washington: The National Academies Press.

National Science Board. 2016. Science and Engineering Indicators. Available online: https://nsf.gov/statistics / 2016/nsb20161/uploads/1/nsb20161.pdf (accessed on 9 January 2018).

National Science Foundation. 2017. Women, Minorities, and Persons with Disabilities in Science and Engineering. Available online: www.nsf.gov/statistics/wmpd/ (accessed on 9 January 2018). 
Neumann, Maureen D., Sandra A. Latham, and Maureen Fitzgerald-Riker. 2016. Resisting cultural expectations: Women remaining as civil and environment engineering majors. Journal of Women Minorities in Science and Engineering 22: 139-58. [CrossRef]

Office of Science and Technology Policy. 2016. Women in STEM. Available online: https:/ / obamawhitehouse. archives.gov/administration/eop/ostp/women (accessed on 9 January 2018).

Powell, Abigail, and Katherine J. C. Sang. 2015. Everyday experiences of sexism in male-dominated professions: A Bourdieusian perspective. Sociology 49: 919-36. [CrossRef]

Powell, Abigail, Barbara Bagilhole, and Andrew Dainty. 2009. How women engineers do and undo gender: Consequences for gender equality. Gender, Work \& Organization 16: 411-28.

Powell, Abigail, Andrew Dainty, and Barbara Bagilhole. 2011. A poisoned chalice? Why UK women in engineering and technology students may receive more 'help' than their male peers. Gender and Education 23: 585-99. [CrossRef]

Reilly, Erin D., Kadie Rackley, and Germine H. Awad. 2016. Perceptions of male and female STEM aptitude: The moderating effect of benevolent and hostile sexism. Journal of Career Development 44: 159-73. [CrossRef]

Rhoton, Laura A. 2011. Distancing as a gendered barrier: Understanding women scientists' gender practices. Gender \& Society 25: 696-716.

Ro, Hyuan K. 2011. An Investigation of Engineering Students' Post-Graduation Plans Inside or Outside of Engineering. Doctoral dissertation, Pennsylvania State University, State College, PA, USA. Available online: http:/ / search.proquest.com/docview/902152680 (accessed on 9 January 2018).

Ropers-Huilman, Rebecca, and Kelly Winters. 2011. Feminist methodology in higher education. Journal of Higher Education 82: 667-90. [CrossRef]

Sargent, John F., Jr. 2014. The U.S. Science and Engineering Workforce: Recent, Current, and Projected Employment, Wages, and Unemployment. Congressional Research Service Report No. R43061. Available online: https: / / www.fas.org/sgp/crs/misc/R43061.pdf (accessed on 9 January 2018).

Sassler, Sharon, Katherine Michelmore, and Kristin Smith. 2017. A Tale of two majors: Explaining the gender gap in STEM employment among computer science and engineering degree holders. Social Sciences 6: 1-26. [CrossRef]

Sax, Linda J., Allison Kanny, Tiffani A. Riggers-Piehl, Hannah Whang, and Laura N. Paulson. 2015. “But I'm not good at math": The changing salience of mathematical self-concept in shaping women's and men's STEM aspirations. Research in Higher Education 56: 813-42. [CrossRef]

Sax, Linda J., Hilary B. Zimmerman, Jennifer M. Blaney, Brit Toven-Lindsey, and Kathleen J. Lehman. 2017. Diversifying undergraduate computer science: The role of department chairs in promoting gender and racial diversity. Journal of Women Minorities in Science and Engineering 23: 101-19. [CrossRef]

Sheppard, Sheri, Shannon Gilmartin, Helen L. Chen, Krista Donaldson, Gary Lichtenstein, Özgur Eriş, Micah Lande, and George Toye. 2010. Exploring the Engineering Student Experience: Findings from the Academic Pathways of People Learning Engineering Survey (Technical Report CAEE-TR-10-01). Available online: http:/ / www.engr.washington.edu/caee (accessed on 9 January 2018).

Smith, Kathleen N., and Joy G. Gayles. 2017. "Setting up for the next big thing": Undergraduate women engineering students' postbaccalaureate career decisions. Journal of College Student Development 58: 1201-17. [CrossRef]

Stainback, Kevin, Thomas N. Ratliff, and Vincent J. Roscigno. 2011. The context of workplace sex discrimination: Sex composition, workplace culture, and relative power. Social Forces 89: 1165-88. [CrossRef]

Stake, Robert E. 2005. Qualitative case studies. In The Sage Handbook of Qualitative Research, 3rd ed. Thousand Oaks: Sage Publications, pp. 433-66.

Tatum, Beverly D. 1997. Why Are All the Black Kids Sitting Together in the Cafeteria. New York: Basic Books.

Wang, Ming-Te, and Jessica Degol. 2013. Motivational pathways to STEM career choices: Using expectancy-value perspective to understand individual and gender differences in STEM fields. Development Review 33: 304-40. [CrossRef] [PubMed]

Wijeyesinghe, Charmaine L., and Susan R. Jones. 2014. Intersectionality, identity, and systems of power and inequality. In Intersectionality and Higher Education: Theory, Research, and Praxis. Bern: Peter Lang, pp. 9-19.

Winters, Katherine, Holly Matusovich, and Cheryl Carrico. 2012. So How Did That Go for You? Early Career Engineers' Success in Meeting Goals Set as Undergraduate Seniors. Starkville: American Society of Engineering Education, April. 
Woodcock, Anna, and Diana Bairaktarova. 2015. Gender-biased self-evaluations of first-year engineering students. Journal of Women Minorities in Science and Engineering 21: 255-69. [CrossRef]

Wylie, Alison. 2003. Why standpoint matters. In Science and Other Cultures: Issues in Philosophies of Science and Technology. Edited by Robert Figueroa and Sandra Harding. New York: Routledge.

Wynn, Alison T., and Shelley J. Correll. 2017. Gendered perceptions of cultural and skill alignment in technology companies. Social Sciences 6: 1-28.

$\mathrm{Xu}$, Yonghong J. 2013. Career outcomes of STEM and non-STEM college graduates: Persistence in majored-field and influential factors in career choices. Research in Higher Education 54: 349-82. [CrossRef]

$\mathrm{Xu}$, Yonghong J. 2015. Focusing on women in STEM: A longitudinal examination of gender-based earning gap of college graduates. Journal of Higher Education 86: 489-523. [CrossRef]

$\mathrm{Xu}$, Yonghong J. 2017. Attrition of women in STEM: Examining job/major congruence in the career choices of college graduates. Journal of Career Development 44: 3-19. [CrossRef]

Yin, Robert K. 2014. Case Study Research: Design and Methods, 5th ed. Thousand Oaks: Sage Publications.

(C) 2018 by the authors. Licensee MDPI, Basel, Switzerland. This article is an open access article distributed under the terms and conditions of the Creative Commons Attribution (CC BY) license (http:/ / creativecommons.org/licenses/by/4.0/). 